\title{
ECOPHILOSOPHY AND SYMBOLICAL WORLD OF NATURE: AN ISSUE OF INTERPRETATION
}

\author{
Elena N. Shulga \\ Institute of Philosophy, Russian Academy of Sciences, Moscow, Russian Federation
}

\begin{abstract}
The need to expand the range of issues traditional for the philosophy of nature, led to the emergence of ecophilosophy - a philosophical discipline, focused on the knowledge of various aspects of life through the synthesis of knowledge about the man, the natural environment and the essence of the living. Having abandoned the fundamental position of the philosophy of nature - anthropocentrism, ecophilosophy at first replaced it with the principle of biocentrism, when all living beings have an unconditional value, and then with the principle of ecocentrism, according to which the recognition of the sovereignty of the natural world requires that we give up any desire to dominate it. At the same time, ecophilosophy, relying on the methods of hermeneutics, searches for the answer to the question of how the symbolic world of nature is environmentally "arranged" and how it is interpreted. The hermeneutics of the symbolic world of nature becomes, in this case, "biogermeneutics", since it is not a matter of interpreting texts created by man, but of natural texts. The rules of interpretation here are recorded through prohibitions and regulations, their effectiveness and effectiveness are verified in practice and subsequently fixed in the ecological tradition of a particular people. By reconstructing the meaning of natural texts on the basis of the hermeneutical approach, we learn not only the specifics of figurative thinking and the symbolic language of the people, but also the perception of the symbolic world of nature in the human culture. The presence of archaic elements in the ecological thinking of modern man confirms the continuity of knowledge and tradition, the desire of a person to record and transmit the received information of everyday life, preserving them as creative patterns of perception of the unity of man and nature. They attach importance not only to the purely pragmatic, useful for survival in specific natural conditions, but also the universal and philosophical significance. In the article on the material of the folklore of the peoples of Russia it is shown how the continuity of knowledge within the world view is preserved and how the original archaic symbolic world of the images of nature acquires a value meaning and a philosophical status.
\end{abstract}

Key words: ecophilosophy, hermeneutics, culture, prescriptions, beliefs, prohibitions, meanings, interpretation.

УДК 140.8

ББК 87.2

\section{ЭКОФИЛОСОФИЯ И СИМВОЛИЧЕСКИЙ МИР ПРИРОДЫ: ПРОБЛЕМА ИНТЕРПРЕТАЦИИ}

\author{
Елена Николаевна Шульга \\ Институт философии РАН, г. Москва, Российская Федерация
}

\begin{abstract}
Аннотация. Необходимость расширить круг вопросов, традиционных для философии природы, привела к возникновению экофилософии - философской дисциплины, ориентированной на познание различных аспектов проявления жизни на основе синтеза знаний о человеке, природной среде и сущности живого. Отказавшись от основополагающей позиции философии природы - антропоцентризма, экофилософия заменила его вначале принципом биоцентризма, когда безусловной ценностью обладают все живые существа, а затем и принципом экоцентризма, согласно которому признание суверенности естественного мира требует, чтобы мы отказались от любого стремления владычествовать над ним. При этом экофилософия, опираясь на методы герменевтики, осуществляет поиск ответа на вопрос о том, как экологически «устроен» символический мир природы и как он интерпретируется. Герменевтика символического мира природы становится в этом случае «биогерменевтикой», поскольку речь идет не об истолковании текстов, созданных человеком,
\end{abstract}


но природных текстов. Правила истолкования здесь фиксируются посредством запретов и предписаний, их действенность и эффективность проверяется на практике и впоследствии закрепляется в экологической традиции конкретного народа. Реконструируя смысл природных текстов на основе герменевтического подхода, мы познаем не только специфику образного мышления и символического языка народа, но и восприятие символического мира природы в человеческой культуре. Наличие элементов архаики в экологическом мышлении современного человека подтверждает преемственность знания и традиции, стремление человека фиксировать и передавать полученные сведения обыденной жизни, сохраняя их как творческие образцы восприятия единства человека и природы. Им придается значение не только сугубо прагматическое, полезное для выживания в конкретных природных условиях, но и общечеловеческое и философское значение. В статье на материале фольклора народов России показано, как сохраняется преемственность знаний внутри миропонимания и как первоначальный архаический символический мир образов природы приобретает ценностное значение и философский статус.

Ключевые слова: экофилософия, герменевтика, культура, предписания, верования, запреты, смыслы, интерпретация.

Термин «экофилософия» возник в конце ХХ в. в связи с необходимостью философского осмысления новейших результатов биологических дисциплин и потребностью расширить круг вопросов, традиционных для философии природы. Акцентируя внимание на сути процессов, происходящих в живых системах разного уровня организации, экофилософия не ограничивается изучением только биологических объектов, рассматриваемых с точки зрения их функционирования, но постепенно включает в проблемное поле своих исследований широкий комплекс вопросов социоприродного и даже социокультурного значения. Такая направленность био- и экофилософии позволяет характеризовать ее как философскую дисциплину, ориентированную на познание самых разных аспектов проявления жизни, рассматриваемой с естественнонаучных, социальногуманитарных и философских позиций. Тем самым экофилософия предстает как новая философия природы, которая формирует и развивает свой научный аппарат на основе синтеза междисциплинарных знаний о человеке, природной среде и сущности живого. Особую актуальность в экофилософии приобретают вопросы взаимовлияния человека и природной среды, становящиеся центральным фактором, определяющим культурный ландшафт жизнедеятельности отдельного народа.

Создавая научную картину мира живой природы, экофилософия оказывает обратное влияние на современную научную картину мира. При этом главное внимание уделяет фундаментальным открытиям, понятиям и теориям естественных наук в их приложении к биологии и экологии; выведению философских следствий, касающихся понимания жизни, уровней структурной организации живого, его границ. Основным стимулом развития этого направления исследований стала интеграция биологических наук с науками о неживой природе. Например, на микроуровне это привело к возникновению молекулярной биологии, которая изучает специфику молекулярных механизмов живого. Вместе с тем, глобальный эволюционизм придал теории биологической эволюции планетарное измерение. Схожие тенденции можно обнаружить и в концептуальных построениях, касающихся соотношения «человек - природа» или «человек и окружающий мир», мировоззренческий смысл которых зависит от того, что является центральным, исходным объектом изучения, по отношению к которому выстраивается та или иная теория или целая мировоззренческая позиция.

Так, для антропоцентризма человек это венец эволюции, поэтому его интеллектуальные устремления, согласно антропоцентрическому мировоззрению, должны быть обращены к преобразованию естественной природы и направлены на создание техносферы. Предполагается, что техносфера не просто сменит биосферу в ее естественном природном качестве, но будет в состоянии поддерживать устойчивое развитие природной среды, и при этом будут удовлетворяться все растущие потребности человечества. Однако стремление к абсолютному господству над природой на фоне безудержного потребления природных ресурсов, может привести к разрушению эволюционно организованной цело- 
стности биосферы и составляющих ее экосистем [11, p. 87-104]. Осознавая это, многие ученые сегодня признают, что ориентация человечества на максимальное потребление природных ресурсов стремительно разрушает окружающую среду, делая иллюзорной абсолютизацию возможностей техногенной цивилизации, нивелируя антропоцентризм как универсальный подход в решении проблемы соотношения природного и социального. В противоположность антропоцентризму альтернативной позицией, направленной на сохранение и поддержание стабильности биосферы как экологической ниши человечества, выступает биоцентризм, согласно которому безусловной ценностью обладают все живые существа, обитающие на Земле, весь биос рядом с человеком. Согласно биоцентризму, использование природных ресурсов должно ограничиваться только потребностями, обеспечивающими сохранение человечества как вида. Однако эта точка зрения выглядит столь категоричной, что представляется неприемлемой для многих стран. Кроме того, она должна быть скорректирована различными аргументами экономического, политического и правового значения [12]. Отстаивая ценностные ориентиры экологического направления мысли внутри философии, исследователи настаивают на том, что центральным объектом экофилософии является природа. Они формулируют концепцию экоцентризма, которая не противостоит биоцентризму, но дополняет его. «Термин “экоцентризм” описывает радикальную позицию, согласно которой признание самоценности естественного мира требует, чтобы мы вышли за пределы нашей чисто человеческой точки зрения и отказались от любого стремления владычествовать над ним. Поскольку экоцентризм в настоящее время является признанным принципом экофилософии, одной из главных задач экофилософии стало выяснение тех концептуальных ресурсов, которые помогают утвердить это новое видение, и отказ от тех, которые на это неспособны» [10, p. 22].

Экофилософия признает наличие признаков техногенной цивилизации как позитивных, так и негативных, в частности, отмечая техногенное давление на окружающую среду, влияние на человека, его здоровье и менталь- ность. Поэтому призыв к сохранению устойчивости живой природы и поддержанию ее способности к саморегуляции становится одним из главных тезисов современной философии природы. Кроме того, этот тезис согласуется с наиболее актуальным требованием глобально-экологического значения: он касается поддержания эволюционно организованной целостности биосферы за счет сохранения существующего разнообразия составляющих ее живых организмов и экосистем. Наряду с этим положением общефилософский смысл приобретают высказывания, касающиеся определения места живого в сфере человеческого бытия. Так, о гуманном отношении к живому пишут многие философы, рассматривая его как необходимый этап нравственной переориентации общества. Ученые совместно с философами разрабатывают основы биоэтики и биополитики, экологической биоэтики и биомедицинской этики и при этом исходят из принципа самоценности всех живых существ. «Каждое проявление (форма) жизни, - подчеркивает М.В. Гусев, - уникально и требует защиты независимо от практической ценности. Численность всех таксонов (диких или одомашненных) должна быть по крайней мере достаточной для выживания» [3, с. 253]. Размышления о ценности природы и всех живых существ ее населяющих имеют силу и в отношении к «видовой сущности» человека, и при этом принимается во внимание социальный способ существования современного человека внутри человеческого сообщества, внутри культуры.

Рассуждая о человеке и сущностных критериях его жизни, Б.Г. Юдин перечисляет те конкретные проблемы, которые не имели аналогов в прошлом опыте человечества. «Среди этих проблем - идентичность человеческого существа, определение начала и конца индивидуальной человеческой жизни, приемлемость различных критериев смерти человека, в том числе критериев полной или частичной смерти мозга, право собственности на генетическую информацию и вопросы защиты ее конфиденциальности» [8, с. 275]. Как можно заметить, эти проблемы не только этикомедицинского характера, но и философского значения. Таким образом, экофилософия, определяя онтологический статус природы и ак- 
сиологическую, ценностно ориентированную перспективу развития всех ее систем, учитывает интересы человеческого сообщества, изучает многообразные способы существования человека в среде, которые находят отражение в многообразии культур. Особую актуальность приобретают вопросы взаимовлияния человека и природной среды. Именно «взаимовлияние», как будет показано в данной статье, оказывается центральным фактором, определившим культурный ландшафт жизнедеятельности конкретного народа.

Обращение к истокам зарождения культуры народов России (а их сегодня насчитывается более 180 !), к их верованиям и традиции, рассматриваемой, в том числе, с точки зрения формирования рационального отношения к природной среде, делает актуальным объединение усилий представителей самых разных дисциплин. Философы, постигающие суть взаимовлияния человека и природы, подчеркивают необходимость разработки такой методологии, которая бы отвечала междисциплинарному характеру современных научных исследований в этой области знания. Такая задача связана и с обоснованием конкретного подхода, направленного на познание природных условий жизнедеятельности людей, повлиявших на миропонимание конкретного народа и становление культуры в ее многообразных формах проявления. Например, в сфере традиционного природопользования. Вместе с тем, в фокусе внимания исследователей оказываются народы с их традиционным менталитетом и исторически сложившимися культурными ценностями. Именно внутри традиционных культур различных народов России мы обнаруживаем такие образцы отношения к природе, которые обладают символическим смыслом как для самих этих культур (и народов), так и «для нас». В целом символические смыслы образов природы могут характеризоваться как фундаментальные компоненты экологического понимания взаимоотношения человечества и природной среды.

Рассматривая функционирование культуры в природной среде с позиции того, что ее создает и предопределяет, мы познаем жизнь культуры, ее внутренний смысл; мы постигаем не только отдельные символы в их значе- нии, но рассматриваем движение смысла. Решая эту эпистемологическую задачу в контексте проблематики экофилософии, мы закономерным образом подходим к вопросу отношения человека к природе, рассматривая это отношение в категориях добра и зла, ответственности и разумной необходимости, пользы и блага, долга и ценности. Тем самым ценность природы, ценность всего живого и ценность жизни человека образуют замкнутый круг постоянно происходящих взаимодействий. Движение смысла, определяющего характер каждого этапа взаимодействия внутри такого рода целостности, мы познаем благодаря культурно-историческому контексту восприятия той среды (природной и социальной), в которой человек живет и действует. Тем самым философский, метафизический аспект проблематики жизни конкретизируется как направленный непосредственно на ее понимание. Причем именно представители современной «философии жизни» используют понятие «жизнь» как основание для понимания культуры. «Как мы теперь знаем, - пишет В.Г. Борзенков, - жизнь и культура находятся в столь тесном пространственном, временном и функциональном перекрытии, что с полным основанием можно говорить: “культура укоренена в жизни”, “жизнь прорастает человеческой культурой” и пр. Эти термины и выражения, взятые в общем виде, правильно выражают суть дела. ...Если им не придавать статуса объяснительных утверждений (тогда это будет чистая метафизика), а видеть в них предварительное выражение сути дела, предполагающее раскрытие механизмов этих процессов, тогда они оказываются на удивление точными. И хотя высшие этажи и уровни ценностей, несомненно, имеют, главным образом, социальные и сугубо антропологические корни, само отношение значимости, специфическим выражением которых они являются, возникает вместе с живой природой и вместе с ней посредством ее прорыва достигает высот культуры, науки, нравственности, эстетики и религии» [2, с. 423].

\section{Символический мир природы: герменевтика образов}

Одним из способов познания и адекватным подходом к выяснению глубинных основ, 
определивших жизнедеятельность людей, является герменевтический взгляд на культуру. Этот метод эффективен и для выяснения скрытого смыслового содержания уже сложившихся экологических императивов, присущих различным народам и являющихся непременным атрибутом их культурной традиции. Характеризуя образ мира конкретного народа, нельзя не учитывать, что природа, климат, природный ландшафт обитания влияют не только на образ жизни людей, но и на стратегию выживания в неблагоприятных природных условиях. Как пишет Тейяр де Шарден, «изучаемый сам по себе в узком плане антропологами и юристами человек - нечто весьма малое и даже умаляющее. Слишком выделяющаяся индивидуальность человека маскирует собой целостность, и наш рассудок, рассматривая человека, склонен дробить природу и забывать о ее глубоких связях и безграничных горизонтах - впадать в дурной антропоцентризм» [5, с. 40]. Поэтому предлагаемый герменевтический взгляд на культуру может быть уместен, прежде всего, с точки зрения интерпретации культурных символов, понимания целей, а также правил их использования носителями культуры в каждой конкретной жизненной ситуации. При этом экофилософия, опираясь на методы герменевтики, осуществляет поиск ответа на вопрос о том, как экологически «устроен» символический мир природы и как он интерпретируется. Это значит, что методы интерпретации текстов письменной культуры могут быть приложимы и в отношении жизненных и житейских «ситуаций», сохраненных в устной традиции. В особенности интерпретация необходима там, где на первое место выдвигается диалог с представителем «иной» культуры. В этом случае объяснение «для другого», «чужого» может быть фактом культурно обоснованным, но требующим дополнительного объяснения. Между тем, в коммуникативных актах с представителями «своей» культуры, истолкование равнозначно объяснению и направлено на понимание прагматических целей, корректирующих поведение человека как представителя данной культуры. Например, правила, регламентирующие поведение человека в природе и своем окружении у народов Сибири связаны с различными запретами и предписани- ями. В языке этих народов (у нивхов, эвенков, эвенов, хантов, мансов) запреты обозначаются терминами, близкими по смыслу русским словам «грех», «нельзя», «табу», «страшно». Предостерегающие предписания выстраиваются по принципу «не делай того-то, а сделаешь - будет так-то» и являются прямыми указаниями на то, что можно, а что нельзя делать. «Лесного голубя убивать нельзя - грешно, можно разориться», «Не бери из гнезда последнее яйцо» [1, c. 121] - так учат доганы, конкретно указывая на то, чего делать нельзя. При этом скрытый подтекст и более широкий смысл запрета касается понимания границ вмешательства в живую природу и ее ресурсы.

Большое распространение в культуре народов России получили запреты, которые требуют от людей безусловного следования им, но не всегда объясняют мотивы таких действий: «Нельзя скрести пустой котел»; «Нельзя есть в головном уборе - грешно»; «Нельзя давать ребенку шумно играть - станет незнайка»; «Живую рыбу не следует резать ножом поперек - рыбы не станет. Резать можно только вдоль»; «Рыбу нельзя пинать, бросать на пол и вообще небрежно с нею обращаться. Рыбаку будет неудача»; «Беременную женщину нельзя пугать: ребенок может быть немым; нельзя показывать покойника»; «Нельзя хвалиться и шуметь, идя на охоту, - не будет удачи» (эвенки). Предписания социального значения связаны с утверждением в сознании и менталитете народа принципа жизни как важного условия мирного сосуществования людей внутри сообщества. Этот принцип жизни толкуется так: благополучие коллектива (семьи, сообщества, группы) зависит от благополучия и правильного поведения каждого члена коллектива. Отсюда и запреты, смысл которых очевиден: «Нельзя направлять любое острие на человека»; «У женатых волосы должны стричь только их жены, чтобы грехи их мужей не перешли к стригущему» (якуты).

На первый взгляд некоторые правила поведения ничем не мотивированы. Но если в одних случаях запрет на действия следует понимать буквально (потому что нельзя!), то в иных случаях нарушение обычаев - вмешательство во взаимоотношения мужа и жены 
носит упреждающий характер угрозы для того, кто не соблюдает обычаи.

В случаях, касающихся запретов на какие-то коммуникативные действия, сами эти действия могут предполагать партнерство с другими людьми, в том числе, партнерство с природой. Например, «При первом посещении чума не вноси своей еды, чтобы не обидеть хозяина». «Нельзя выражать неудовольствие малой добычей, чтобы не рассердить духахозяина»; «Зверя не ругай - рассердится». Нарушение запрета и последствия невыполнения предписаний может повлечь за собой различные несчастья, в первую очередь касающиеся здоровья самого «нарушителя», членов его семьи или повлиять на благосостояние: «Нельзя свистеть в доме - умрет ктото» (ханты.). Сравним: «Нельзя свистеть в доме - денег не будет» (русские).

Рассмотрим примеры, в которых находит отражение тенденция одухотворения природы, анимизм и фетишизм, вера в сверхъестественные силы природы: «Нельзя рубить одиночное дерево - на нем живет дух-хозяин местности»; «Брать угли острым орудием грех: огненный дух боится»; «Нельзя помешивать огонь острым предметом - не любит дух-хозяин огня» (эвены) [6, с. 284]. Замечу, что аналогичный запрет мы встречаем у Пифагора, который учил «Огонь ножом не разгребай!», что наиболее продвинутые ученики должны были понимать не буквально, но как очень тонкое психологическое наблюдение не раздражай гневливого человека! Или «Через весы не переступай, то есть знай меру и не присваивай себе большего, чем заслуживаешь» [7, с. 80-81].

Многие предписания, рекомендации и запреты, связанные с живыми существами, используют мифологическое объяснение и раскрывают сущность символического, а порой, мистического восприятия природы: «Нельзя трогать гусеницу - это душа рогатого скота» (якуты); «Кукушку нельзя убивать это запрет. Раньше кукушка человеком была»; «Кукушку нельзя убивать, потому что это женщина. Кукушка когда кричит, читает слова Торума». (Торум в мифологии хантов - это верховное божество).

Сравнивая различные высказывания, предписания и запреты с позиции герменев- тического подхода, можно заметить, что все они указывают на некоторые смысловые соответствия, которые в самих этих текстах подразумеваются. Когда высказывания касаются конкретных явлений (и прямо указывают на них) или, напротив, передают скрытый смысл содержащегося в них знания, то истолковывая сюжет или конкретный образ, мы получаем представление о его специфической роли в миропонимании народа, в первую очередь исходя из понимания смысла такого рода посланий, где природа и человек воспринимаются в их непосредственной близости друг к другу. При этом символический контекст, если он обнаруживает себя в тексте высказывания, прямо или косвенно создает эпистемологический фон, в контексте которого человек живет, действует и воспринимает предназначенное ему предписание. Интерпретируя его, человек ассоциирует себя с объектами природы и привносит смысл собственного понимания в образы воспринимаемых (или воображаемых) объектов, подвергая истолкованию любые «сюжеты». Интерпретация «сюжета» основывается на предварительно усвоенном контексте тех многочисленных образов, которые уже созданы и существуют в менталитете народа как «историческая память», как прошлый опыт миропонимания (примитивного, архаического, религиозного). Это дает основание утверждать, что интерпретация сопровождает практически все этапы становления культуры и общества, поддерживая статус развитой, жизненно важной познавательной и интеллектуальной способности человека - его способности транслировать знание, например, в образной форме.

В качестве примера использую мотив чудесной щуки - сказочного образа, известного нам из литературы, где щуке предписано исполнять любые «хотения» человека. В народной врачебной практике образ чудесной (исцеляющей недуги) щуки ассоциировался с лечебными свойствами ее зубов, благодаря которым образ чудесной щуки развился в заговор от грыжи. Наиболее распространенный способ лечения этой болезни - «загрызение» грыжи зубами щуки. Старинные лечебники рекомендуют мазать салом больное место перстом или при помощи щучьего зуба, функция которого сводится к устрашению болез- 
ни. «В обрядах, сопровождающих лечение грыжи, сохранился слабый отголосок того, что щука действительно играла в них предполагаемую роль» [4, с. 167]. В лечении «дело могло начаться с простого упоминания одного имени щуки, чтобы пояснить смысл действия, какое совершал знахарь» [4, с. 168-169].

Итак, благодаря интерпретации, выраженной в форме рекомендации, назидания или предписания, реконструируются и передаются знания и представления человека о природе и ее скрытых возможностях. Этот род знания создает собственный словарь знаков и смыслов, которые не статичны, но развиваются, передаются из уст в уста, из поколения в поколение, создавая целый пласт текстов и образов. Смысл их становится объектом интерпретации и входит в контекст культуры не только конкретного народа, но передается от одного народа к другому, от одной исторической эпохе к другой. Так поддерживается преемственность знаний, архаические следы которого указывают на длительный период истории народа. Вместе с тем, герменевтика образов мира природы в их символическом восприятии позволяет выделить поворотные моменты эволюции знания, развитие которого невозможно приписать идентичности только одной народности или отдельному региону. Существует общая тенденция развития миропонимания, сущность которого раскрывается благодаря интерпретации, в том числе, через «образ - символ - смысл» и эта тенденция проявляет себя в формировании определенного стиля мышления.

На характерный для архаической культуры стиль мышления указывают рассмотренные символические образы живой природы. Но самое загадочное и самое интересное для нас состоит в признании факта жизнеспособности такого рода знания, в признании факта присутствия следов архаического миропонимания внутри современной нам культуры и цивилизации. Вместе с тем, наличие элементов архаики в экологическом мышлении современного человека - это всего лишь подтверждение преемственности знания и традиции, способности и стремления человека фиксировать и передавать полученные сведения обыденной жизни, сохраняя их как творческие образцы восприятия единства человека и природы. Им прида- ется значение не только сугубо прагматическое, полезное или нужное для выживания в конкретных природных условиях, но и общечеловеческое и философское значение.

Образ мира, как и уклад жизни человека конкретной культуры, формировался на основании повседневного практического опыта. Часто жизнь протекала в трудных условиях преодоления природной среды (например, в условиях крайнего Севера и Восточной Сибири). Освоение природы шло параллельно с развитием языка и мышления. При этом функция объяснения складывалась из представлений, которые нацелены на создание таких языковых типизированных конструктов, которые были и понятными, очевидными, и при этом отражали обыденный мир в языковой символической форме. Длительный процесс символического освоения действительности нашел отражение в том виде знания о мире, о котором мы размышляем, оценивая сентенции (запреты, предписания) как наиболее яркие и лаконичные языковые слепки образного мировосприятия в его смысловом выражении. Герменевтический подход к анализу смысла образов природы показывает, что человек конкретной культуры, объясняя нечто, знает то, что он имеет в виду. Предполагается, что человек, соприкасаясь с объектами природы, узнает их и понимает значение каких-то вещей; У него есть соответствующий горизонт представлений о тех значениях, смысл которых он передает и фиксирует в языке. Именно это обстоятельство мы рассматриваем как факт наделенности человека способностью к объяснению и пониманию «себя» в мире природы, наряду с пониманием самой природы. Такова сущность человеческого познания, и она с очевидностью усматривается даже в таких жанрах, каковыми являются малые формы фольклора народов России. О наличие внутренней «логики» этих текстов свидетельствует их диалогичность.

Первоначально архаическое отношение человека к действительности, к миру вещей, явлений и процессов с определением места самого человека в мире в условиях соотнесенности его жизненного уклада с природой средой - не случайное явление. Дело в том, что наряду с характерным для конкретного народа укладом жизни, постепенно создается 
определенный образ мира, в котором находят отражения конкретные культурно-исторические и социальные представления. Постепенно, создаваемые образы и смыслы приобретают общечеловеческое значение; этот процесс находит отражение в языке и при этом дает представление об общей направленности становления и развития человеческого понимания и познания, для которого наблюдаемый мир природы - это символический мир проявленных значений, смыслов, знаков, меток. Это мир, где корректируемые культурной традицией собственные действия человека, его поступки имеют смысл как для него самого, так и для окружающей его среды - природной и социальной.

Природа реагирует на поведение и поступки человека, что следует из приведенных примеров архаических запретов. Вспомним, например, «Кукушку нельзя убивать - это запрет. Раньше кукушка человеком была». Это «очеловечивание» кукушки - ценностное сближение с человеком - в доступной форме указывает на то, что природа страдает от неправильного поведения человека подобно тому, как страдает сам человек.

Символические образы природы не обязательно антропоморфны. На это указывают предостережения другого рода, например, «Брать угли острым орудием - грех: огненный дух боится»; «Нельзя помешивать огонь острым предметом - не любит дух-хозяин огня»основаны на интерпретации поведения духов, то есть сущностей, нечеловеческих созданий, чье поведение и мотивы непредсказуемы и непостижимы - как человек может понять нечеловека? В этом случае интерпретация основана на переживании негативных последствий уже совершенных в прошлом действий. Человек уязвим и часто подвержен губительному воздействию стихий природы, а его неправильные действия по отношению к живому могут принести страдания ему самому. Следовательно, стремясь избежать собственных страданий, человек вынужден предвидеть и прогнозировать реакцию природы, в том числе якобы производимую с помощью неких воображаемых нечеловеческих сущностей; и он вынужден вступать в диалог с природными «существами», которые также уязвимы. Поэтому партнерство человека и природы (вместе с населяющими ее суще- ствами или даже духами) наступает только в случае правильного прочтения смысла знаков, примет и предзнаменований.

Герменевтику символического мира природы следует называть «биогерменевтикой», поскольку речь идет не об истолковании текстов, созданных человеком, но природных текстов [9, p. 658-659]. Правила истолкования в этом случае фиксируются посредством запретов и предписаний, их действенность и эффективность проверяется на практике и впоследствии закрепляется в экологической традиции конкретного народа. Природа знаков и предзнаменований изменчива и напрямую зависит от поведения и изменения окружающей среды. Но при этом следует учесть различие между анимистической и панпсихической традициями: если панпсихизм наделяет все создания природы божественной душой, а природа сама становится богом, то в анимизме природа душ различна у человека и природных духов. Осознавая это, человек организует мир, выстраивая своеобразную иерархию «одушевленной» природы, в которой сам человек отнюдь не является высшим существом, поскольку вынужден обращаться за помощью к духам-покровителям. При этом, если с личными и семейными духами-покровителями можно было общаться без чужого посредничества, то с духами более высоких рангов требовалось прибегать к посредничеству хитрых и догадливых людей, умеющих говорить с духами - к жрецам, шаманам, колдунам, предсказателям.

Во многих архаических культурах человек-охотник просит прощения за убийство добычи, часто он заранее просит разрешения на причинение смерти своей жертве. Он рассчитывает на правильное понимание природой своих действий, приносит жертвы духам, надеясь на их милость и правильное истолкование его послания. Таким образом, действия, знаки и послания, которыми обмениваются человек и природа в образе духов и демонов, образуют некий интегральный символический мир, в котором на равных взаимодействует символика действий и посланий человека и воспринимаемая им «символика» природы ожидаемый отклик природы, знак, подтверждающий, что послание услышано и правильно понято природой. Эти знаки-символы, по сути 
дела, представляют собой «биосимволы», символы живого, поскольку природа представляется человеку как живая целостность, наполненная «живыми» духами-посредниками.

Возможность подобной архаической биогерменевтики обусловлена, с одной стороны, широким смысловым диапазоном экологических биосимволов. С другой стороны, она поддерживается общей целью биологических систем (природных и человеческих) - выживанием в условиях эволюционирующей окружающей среды. При этом стратегия выживания также меняется, будучи ответом на постоянные изменения условий существования живых существ. Но, несмотря на все изменения условий окружающей среды и стратегических откликов на эти изменения, постоянной остается цель взаимного приспособления и поддержания экологического равновесия природы и живых существ. И это становится особенно понятно с позиции современного биогерменевтического диалога, начало которого мы обнаруживаем уже в архаических запретах и предписаниях, уходящих корнями в ранние этапы развития человечества.

\section{СПИСОК ЛИТЕРАТУРЫ}

1. Аврорин, В. А. Орочские тексты и словарь / В. А. Аврорин, Е. П. Лебедева. - Л. : Наука, 1978. $-268 \mathrm{c}$.

2. Борзенков, В. Г. Человек в научной картине природы / В. Г. Борзенков // Философия природы сегодня. - М. : «Канон +» : РООИ «Реабилитация», 2009. - C. 399-424.

3. Гусев, М. В. Биоцентризм как базис биоэтики и биологическое образование. Миссия России / М. В. Гусев // Гуманитарная биология. Терминологический словарь (тезаурус) / под ред. А. В. Олескина. - М. : Изд-во МГУ, 2009. - С. 251-262.

4. Познанский, Н. Заговоры. Опыт исследования происхождения и развития заговорных формул. Репринт издания 1917 года. Петроград / Н. М. Познанский. - М. : Индрик, 1995. -352 с.

5. Тейяр де Шарден, П. Феномен человека / П. Тейяр де Шарден. - М. : Наука, 1967. - 240 с.

6. Худяков, И. А. Краткое описание Верхоянского округа / И. А. Худяков. - Л. : Наука, 1969. - 441 с.

7. Шульга, Е. Н. Когнитивная герменевтика / Е. Н. Шульга. - М. : Российская академия наук. Институг философии, 2002. -235 c.

8. Юдин, Б. Г. Биомедицинская этика / Б. Г. Юдин // Гуманитарная биология. Терминоло- гический словарь (тезаурус)/ под ред. А. В. Олескина. - М. : Изд-во МГУ, 2009. - С. 273-278.

9. Favareau, D. Essential Readings in Biosemiotics. Anthology and Commentary / D. Favareau. - Dordrecht : Springer, 2010. -880 p.

10. Griffin, J. On the origin of beauty: ecophilosophy in the light of traditional wisdom / J. Griffin. - Bloomington : World Wisdom Inc., 2011. $-385 \mathrm{p}$.

11. Krassilov, V. A. Ecosystem theory of evolution and social ethics / V. A. Krassilov // Biology Forum. 1994. - Vol. 87, № 1. - P. 87-104.

12. Masters, R. D. Biology and politics. Linking nature and nurture / R. D. Masters // Ann. Rev. Sci. 2001. - Vol. 4. - P. 345-369.

\section{REFERENCES}

1. Avrorin D.A., Lebedeva E.P. Orochskie teksty i slovar [Oroch's Texts and Vocabulary]. Leningrad, Nauka Publ., 1978. 268 p.

2. Borzenkov V.G. Chelovek v nauchnoy kartine prirody [The Role of Man in the Scientific Picture of the Nature]. Filosofiya prirody segodnya [Philosophy of Nature Today]. Moscow, Kanon+ Publ., 2009, pp. 399-424.

3. Gusev M.V. Biotsentrizm kak bazis bioetiki i biologicheskoe obrazovanie. Missiya Rossii [Biocentrism as a Basis of Bioethics and the Biological Education. Mission of Russia]. Oleskin A.V., ed. Gumanitarnaya biologiya. Terminologicheskiy slovar (tezaurus) [Humanities' Biology. Terminological Vocabulary (Thesaurus)]. Moscow, Izd-vo MGU, 2009, pp. 251-262.

4. Poznanskiy N. Zagovory. Opyt issledovaniya proiskhozhdeniya i razvitiya zagovornykh formul [Incantations. An Essay on Studying the Origin and Development of Incantation Formulae]. Moscow, Indrik Publ., 1995. 352 p. (Reprint of 1917 edition, Petrograd).

5. Teilhard de Chardin P. Fenomen cheloveka [The Phenomenon of Man]. Moscow, Nauka Publ., 1967. $240 \mathrm{p}$.

6. Khudyakov I.A. Kratkoe opisanie Verkhoyanskogo okruga [Brief Description of the Verkhoyansk District]. Leningrad, Nauka Publ., 1969. $441 \mathrm{p}$.

7. Shulga E.N. Kognitivnaya germenevtika [Cognitive Hermeneutics]. Moscow, Russian Academy of Sciences, 2002. $235 \mathrm{p}$.

8. Yudin B.G. Biomeditsynskaya etika [Biomedical Ethics]. Oleskin A.V., ed. Gumanitarnaya biologiya. Terminologicheskiy slovar (tezaurus) [Humanities' Biology. Terminological Vocabulary (Thesaurus)]. Moscow, Izd-vo MGU, 2009, pp. 273-278. 
E.Н. Шульга. Экофилософия и символический мир природы: проблема интерпретации

9. Favareau D. Essential Readings in Biosemiotics. Anthology and Commentary. Dordrecht, Springer, 2010. $880 \mathrm{p}$.

10. Griffin J. On the origin of beauty: ecophilosophy in the light of traditional wisdom. Bloomington, World Wisdom, Inc., 2011. 385 p.
11. Krassilov V.A. Ecosystem theory of evolution and social ethics. Biology Forum, 1994, vol. 87 , no. 1 , pp. 87-104.

12. Masters R.D. Biology and politics. Linking nature and nurture. Ann. Rev. Sci., 2001, vol. 4, pp. 345-369.

\section{Information about the Author}

Elena N. Shulga, Doctor of Sciences (Philosophy), Leading Researcher, Institute of Philosophy, Russian Academy of Sciences, Goncharnaya St., 12, 119019 Moscow, Russian Federation, elena.shulga501@gmail.com

\section{Информация об авторе}

Елена Николаевна Шульга, доктор философских наук, ведущий научный сотрудник, Институт философии РАН, ул. Гончарная, 12, 119019 г. Москва, Российская Федерация, elena.shulga501@gmail.com. 